\title{
CONTRIBUIÇÃO PARA A CONSTRUÇÃO SUSTENTÁVEL: CARACTERÍSTICAS DE UM PROJETO HABITACIONAL ECO- EFICIENTE
}

\section{CONTRIBUTE TO THE SUSTAINABLE CONSTRUCTION: ECO- EFICIENCY PROJECT CHARACTERIZATION}

\author{
Leila Chagas Florim \\ Profissão: Arquiteta \\ Instituição: UERJ \\ Depto: DEMOP - Departamento de Obras e Projetos \\ Endereço: Rua São Francisco Xavier 524, Sala T141 \\ Cep.: 20550-013, Maracanã, Rio de Janeiro. \\ Telefone: (0xx21) 2587-7649 \\ cf 1eila@yahoo.com.br, 1cflorim@uenf.br \\ Osvaldo Luiz Gonçalves Quelhas, D.Sc. \\ Profissão - Professor Universitário \\ Instituição - Universidade Federal Fluminense - UFF \\ Departamento - Departamento de Engenharia Civil \\ Endereço completo - Rua Passo da Pátria, 156 - sala 329 - Bloco "E" - \\ Escola de Engenharia - São Domingos - Niterói - RJ - CEP-24210-240 \\ Telefone e e-mail - (21) 2629-5620 - quelhas@latec.uff.br
}

\section{RESUMO}

A habitação com qualidade é uma necessidade que deve ser satisfeita sem comprometimento dos eco-sistemas existentes. A consciência quanto a finitude dos recursos naturais e à degradação ambiental fomentada pela construção civil vêm despertando preocupação, principalmente devido ao déficit habitacional de 5,4 milhões de novas habitações. A questão ambiental atrelada à gestão empresarial é vista hoje como necessidade de sobrevivência dentro de um mercado competitivo e como forma de sobrevivência do planeta com seus ecosistemas e ciclos de renovação preservados. Dessa forma, propõe-se, através de metodologia exploratória com pesquisa bibliográfica, critérios de planejamento de empreendimentos habitacionais voltados para a construção sustentável, apresentam-se pautados na ecoeficiência técnica e de gestão do empreendimento. Contribui para o estado da arte na Construção Sustentável, dedicando-se a caracterizar e a dar relevância sob o ponto de vista ambiental, social e econômico ao empreendimento, configurando sua eco-eficiência.

Palavras-chave: Construção sustentável. Gestão integrada. Eco-eficiência. 


\begin{abstract}
Dwelling with quality is a need that must be satisfied without endangering the eco-systems, leading companies to assume an ethics posture of environmental valuation. The conscience of natural resources finitude and environmental degradation fomented by Construction come rousing, principally due to 5,4 millions new dwellings deficit. The environmental issue leashed to business management is not seeing as ephemeral, but as a survival requirement inside a competitive market, a community heedful to their consumers and citizens' right as well as to the planet survival with its eco-systems and renewal cycles. On this context, is proposed, through an exploratory methodology and bibliographical research, planning criteria of dwelling projects with focus on sustainable construction. Arouse guided by eco-efficiency techniques and project management, showing as result the gradual reduction of environmental impacts and resources consumption intensity, to a standard, at least, close to the planet uphold capacity. Contribute to the State of the Art on Sustainable Construction, committing on characterize and give relevance, considering environmental, social and economical point of view, configuring its eco-efficiency.
\end{abstract}

Key-words: Sustainable construction. Integrated Management System. Eco-efficiency.

\title{
1. INTRODUÇÃO
}

A habitação é um instrumento de grande importância para o equilíbrio social, pois a casa representa o abrigo natural e seguro da família, sendo esta a célula da estrutura social de um país. Remonta de longa data a questão habitacional no Brasil. A moradia condigna configura um dos mais importantes direitos do homem e o acesso a ela constitui uma das mais legítimas aspirações do cidadão, é uma condição básica para a promoção de sua dignidade, configurando-se assim, em um importante fator de estabilidade social e política. Sendo uma necessidade premente do ser humano, caracteriza valores, cultuados desde a infância, como segurança, abrigo e status, uma vez alcançados, permite que o indivíduo conquiste novos objetivos. Deve atender às necessidades inerentes ao bem morar, sua cultura e valores.

Na segunda metade do século XX, muitos países em desenvolvimento assistiram ao rápido crescimento de suas populações urbanas sem a necessária expansão dos serviços públicos. O resultado é que em praticamente todos os centros urbanos do terceiro mundo, muito pessoas vivem em locais sem infra-estrutura básica, com muito poucos serviços e facilidades (ABREU, 1997, passim). As cidades são divididas tanto socialmente quanto fisicamente. Esta divisão é particularmente evidente em países onde uma pequena elite e classe média convivem com uma população pobre e/ou muito pobre de proporções muito maiores, e a distribuição das riquezas é brutalmente desproporcional, como na América Latina. No Brasil dos anos 90 , as apropriações de renda dos $10 \%$ mais ricos da população 
correspondia a 50\% do total da renda do país. (PELIANO, 2004). A habitação com qualidade é uma necessidade que deve ser satisfeita sem comprometimento dos eco-sistemas existentes, levando as empresas a assumirem uma postura ética de valorização do meio ambiente.

Em 1972, Estocolmo, ocorreu a Conferência das Nações Unidas sobre o Ambiente Humano, a qual oficializou o surgimento de uma preocupação internacional sobre problemas ambientais. Em 1992, a conferência das Nações Unidas sobre o Meio Ambiente e Desenvolvimento, conhecido como ECO 92, resultou na elaboração da Agenda 21, onde foram delineadas diretrizes a serem seguidas pelos 180 países participantes da conferência.

\subsection{CENÁRIO ATUAL}

Há um crescente interesse na redução de impactos ambientais associados ao setor da construção civil, seja na fase de produção de materiais e componentes para edificação, seja na construção, no uso ou na demolição da mesma.

A segregação, a que submete parte da população desprestigiada de serviços sociais, se apresenta tanto física quanto socialmente, reduzindo a sustentabilidade das ocupações e impactando o meio ambiente.

\subsection{FORMULAÇÃO DA SITUAÇÃO - PROBLEMA}

Os autores identificam carência de literatura acerca da aplicação dos conceitos da sustentabilidade em políticas habitacionais, levando em consideração todas as fases de um empreendimento, e não apenas através de uma visão setorizada do produto ou processo. A necessidade da construção de 5,4 milhões de novas habitações (GONÇALVES, 1998, p. 3), simultaneamente a consciência despertada quanto a finitude dos recursos naturais e à degradação ambiental fomentada pela construção civil, influenciaram os autores na definição da problemática a ser estudada nesta pesquisa.

\subsection{METOdOLOGIA ADOTADA NA CONFECÇÃO DA PESQUISA}

A metodologia adotada é exploratória, por ter sido realizada em área sobre a qual há pouco conhecimento acumulado e sistematizado, com utilização da pesquisa bibliográfica caracterizando-a ao nível de premissas da construção sustentável. Através da análise prospectiva, objetivou-se orientar a tomada de decisões presentes com base em possíveis modificações futuras das variáveis a nível ambiental, social e econômica. Permite tornar o 
gestor um comandante e não a vítima do processo, melhorando qualitativamente os planos realizados e a base de informação disponível na tomada de decisão gerencial.

Os subsídios que permitiram compor o conteúdo do trabalho foram coletados através de pesquisas na Internet e bibliográficas, com informações relevantes à compreensão, situando o leitor através da abordagem sócio-técnica, em busca da eco-eficiência de suas soluções.

\subsection{QUESTÕES LEVANTADAS}

A seguir serão enumeradas as questões que deverão ser esclarecidas ao longo do trabalho:

1- Existem pesquisas e/ou experiências no Brasil realizadas sobre eco-eficiência e construção sustentável com foco na habitação?

2- De que forma o setor da construção civil de habitações pode ser beneficiado sob o ponto de vista da construção eco-eficiente?

\section{REVISÃO DA LITERATURA}

Há uma diversidade de interações aplicáveis em empreendimentos habitacionais de uso social que visam à preservação do meio-ambiente. A falta de acuro se mostra presente em todas as etapas da sua elaboração, desde a fase de planejamento até a fase de manutenção, quando esta é contemplada. É preciso que se faça uma investigação prévia do passivo ambiental do terreno, analisando os condicionantes do meio físico, efetivação de medidas de mitigação de impactos ambientais, entre outros aspectos, sua ausência tem levado a situações de degradação ambiental. O resultado se manifesta através de prejuízos ao próprio empreendimento, acarretando redução da qualidade de vida e elevação dos custos (empreendedores, usuários, população circunvizinhança e Poder Público), propiciando impactos ambientais que geralmente extrapolam a área do projeto.

Medidas corretivas mostram-se onerosas financeiramente e socialmente devido à vultuosidade dos recursos necessários para reverter este quadro, com obras freqüentemente insatisfatórias em nível de desempenho. É necessária a adoção integrada de medidas preventivas, que considerem, além do próprio empreendimento, os impactos ambientais que extrapolam a área de intervenção e os aspectos sociais envolvidos. Tais medidas podem ser 
efetivadas, para cada fase do empreendimento, por meio de instrumentos de planejamento e gestão ambiental, os quais surgiram e vêm se desenvolvendo no bojo da evolução da abordagem da questão ambiental, e cujos princípios e procedimentos têm sido crescentemente adotados em diversos países.

A responsabilidade social empresarial é um tema de grande relevância nos principais centros da economia mundial. Nos Estados Unidos e na Europa proliferam os fundos de investimento formados por ações de empresas socialmente responsáveis. O Sustainability Index, da Dow Jones, por exemplo, enfatiza a necessidade de integração dos fatores econômicos, ambientais e sociais nas estratégias de negócios das empresas. Normas e padrões certificáveis relacionados especificamente ao tema da responsabilidade social, como as normas AS 8000 (relações de trabalho) e AA 1000 (diálogo com partes interessadas), vêm ganhando crescente aceitação.

A criação de "Indicadores" (sociais, econômicos, qualidade e ambientais), normas e padrões fazem parte do esforço em disseminar a responsabilidade empresarial no Brasil. Ao mesmo tempo em que servem de instrumento de avaliação para as empresas, reforçam a tomada de consciência dos empresários e da sociedade brasileira sobre o tema.

A seguir serão fornecidas algumas definições importantes, relacionadas a sustentabilidade das construções e do ambiente em que se insere.

\subsection{Desenvolvimento Sustentável}

Termo criado em 1987, definido no Relatório Nosso Futuro Comum da "Brundtland Commision" (Comissão Mundial para Meio Ambiente e Desenvolvimento) como "desenvolvimento que satisfaz as necessidades do presente sem comprometer a capacidade das futuras gerações de satisfazer as suas próprias necessidades". (BRUNDTLAND, 1999)

Busca conciliar o desenvolvimento econômico com a preservação ambiental e, ainda, levando em consideração os aspectos sociais. A proteção do ambiente não é um assunto a ser visto de forma estanque, no que diz respeito a desenvolvimento econômico, ele permeia todo o universo das decisões políticas. E um grande sistema onde o sucesso depende da sinergia do todo. (MENDES, 2003)

Desde a década de 50 que o país convive com um processo crescente de segregação física e social (ABREU, 1997, p.71 et seq.). Os aspectos econômicos, sociais e ambientais devem ser contemplados em qualquer projeto habitacional, se revelando em função do uso 
eqüitativo da infra-estrutura urbana. A cidade, ou área metropolitana, deve servir o cidadão como modelo de civilização sustentável. - eqüitativa, harmoniosa e ancorada nos princípios de justiça social e autonomia individual.

\subsection{Eco-eficiência}

Além de permitir uma real adequação das atividades humanas com as necessidades do meio ambiente, buscar a eco-eficiência é, acima de tudo, utilizar uma ferramenta estratégica para a competitividade. O cuidado ambiental, bem como a adequação à legislação vigente através do desenvolvimento de métodos e técnicas de produção mais limpa, é uma preocupação que, a cada dia, cresce e se solidifica como o caminho mais seguro para se obter um melhor padrão de desenvolvimento.

A eco-eficiência é alcançada mediante o fornecimento de bens e serviços a preços competitivos, que satisfaçam as necessidades humanas e tragam qualidade de vida, promovendo ao mesmo tempo uma redução progressiva dos impactos ambientais e da intensidade do consumo de recursos ao longo do seu ciclo de vida, a um nível, no mínimo, equivalente à capacidade de suporte estimada da Terra.

É uma ferramenta do desenvolvimento sustentável, dentro do conceito do pensar globalmente agindo localmente, considerando de um lado o aspecto econômico, de outro o ecológico, e ambos associados à visão social, onde a responsabilidade é de todos.

Dos recursos extraídos da terra, $60 \%$ são consumidos nos edifícios, o que tem aumentado o uso de sistemas construtivos ecologicamente apropriados, assim como de materiais ecologicamente corretos e em si só recicláveis e/ou reciclados, incluindo-se uma análise científica dos seus ciclos de vida, cujo conceito inclui todos os custos produzidos desde a fabricação até o descarte de um material específico. (CIMINO, 1992, p.8)

\subsection{Construção Sustentável e suas premissas de atuação}

A Construção Sustentável aborda o Desenvolvimento Sustentável no orbe da indústria da construção civil, ou seja particulariza um conceito global, sendo assim pressupõe também a interdisciplinaridade, na medida que sua evolução nos leva a trabalhar com três macro temas que compõe o chamado "triple bottom line", ou seja, os aspectos ambientais, sociais e econômicos. A sinergia entre esses aspectos permeia a aplicação do conceito de Sustentabilidade, onde quer que ele seja aplicado, tanto em nível governamental, como da 
sociedade civil ou na seara empresarial. Pode-se também trabalhar com outras dimensões do desenvolvimento sustentável, como por exemplo os aspectos culturais, tecnológicos e políticos.

Visa o aumento das oportunidades ambientais às gerações futuras, consistindo numa moderna estratégia ambiental, direcionada a produção de edificações mais seguras e saudáveis, fundamentada na: (CIMINO, 2002, p. 5)

- redução da poluição;

- economia de energia e água;

- diminuição da pressão de consumo sobre matérias-primas naturais;

- aprimoramento das condições de segurança e saúde dos trabalhadores, usuários finais e comunidade em geral.

\subsection{Produção + Limpa $(\mathrm{P}+\mathrm{L})$}

Tecnológica e gerencialmente, o sistema produtivo baseado em Produção Mais Limpa (proposta da UNEP, termo em inglês e traduzido - Programa das Nações Unidas para o Meio Ambiente) e Produção Limpa (defendida por organizações ambientalistas e vários centros de P\&D - pesquisa e desenvolvimento) superam a Série ISO14000. Produção Limpa implica em evitar (prevenir) a geração de resíduos. Afeta direta e objetivamente o processo, produto, embalagens, descarte, destinação, manejo de lixo industrial e restos de produtos, comportamento de consumidores e política ambiental da empresa.

As metas da Produção Limpa são baseadas em critérios harmônicos, padrões internacionais elevados e na visão global do mundo e do mercado. É necessário reconhecer a dificuldade de conceber o sistema de produção absolutamente isento de riscos e resíduos. Talvez tenha sido esta a maior justificativa da proposta Mais Limpa, pois Produção Limpa seria então utopia. Por isso, a distinção entre Produção Limpa e Mais Limpa pode parecer apenas sutil, entretanto, as diferenças traduzem a medida exata do quanto se espera conseguir, na reorientação do modelo de produção de bens e serviços.

Produção Limpa e Mais Limpa defendem a prevenção de resíduos na fonte, a exploração sustentável de fontes de matérias primas, a economia de água e energia e o uso de outros indicadores ambientais para a indústria. Produção Limpa vai mais longe, estabelecendo os compromissos para precaução (não usar matérias primas, nem gerar produtos com indícios 
ou suspeitas de geração de danos ambientais), visão holística do produto e processo (avaliação do ciclo de vida) e controle democrático (direito de acesso público a informações sobre riscos ambientais de processos e produtos). Limita o uso de aterros sanitários e condena a incineração indiscriminada como estratégias de manejo de lixo e resíduos.

As Tecnologias Limpas (TL) são medidas drásticas adotadas no sentido inverso dos procedimentos normalmente impostos de cima para baixo. Para que as metas sejam atingidas, os técnicos do Centro Nacional de Tecnologias Limpas - CNTL da Fiergs/Senai-RS/UnidoUnep, chamam de "técnicas de fim-de-tubo".

Com a economia gerada pela TL o preço dos produtos se torna mais atrativo e competitivo. Estes procedimentos, criam modificações conceituais nos processos de produção, alterando desde a configuração do desenho do produto até o lay-out de linhas de produção e equipamento, com uma seqüência operacional mais racional e segura. Acompanhe a seguir o fluxograma de um Projeto de Tecnologia de Produção.

Se a organização implantar o trabalho, aplicando conceitos neste sentido inverso, começando lá do ponto por onde saem os resíduos, atingirá as metas estabelecidas..

Uma vez esclarecidos os conceitos supra citados, na seqüência será feito um apanhado da questão ambiental integrada aos empreendimentos habitacionais de interesse social.

No âmbito da unidade habitacional, encontram-se tanto questões ambientais próximas, quanto ramificações distantes, mas igualmente importantes. A construção de habitações requer, geralmente, adaptação ao terreno no qual sofrerá intervenção. Esta adaptação costuma gerar desmatamento, alteração do seu perfil topográfico, modificando a paisagem local e causando alterações ambientais também na região do seu entorno. Requer, ainda, diversos materiais e componentes construtivos, consome água e energia, gera poeira, resíduos (principalmente entulhos) e ruídos durante as obras. Na fase de ocupação, passa a gerar novos e constantes resíduos (como esgotos e lixo domiciliares), além de gastos com energia através de eletrodomésticos, como por exemplo aparelhos de ar-condicionado fruto de uma concepção errônea de projeto através da falta de acuro com as técnicas de conforto ambiental, e gastos com água tratada, usada indevidamente por falta de consciência ambiental da sua escassez e descaso de projeto pela desconsideração de técnicas de otimização do seu uso.

No rigor de uma visão sistêmica, também se pode corretamente supor, por exemplo, que é ambientalmente insustentável o modelo de construção de uma habitação que, apesar de apresentar um desempenho térmico primoroso, demanda materiais e componentes, cujo processo de produção envolve um elevado consumo de energia. Dentre eles, têm-se notadamente o cimento ( $\mathrm{e}$, por extensão, os blocos de concreto e materiais associados), o 
vidro, o aço, o alumínio e demais produtos metálicos, os componentes cerâmicos, louças e metais sanitários e assim por diante. Ainda há muito a ser desenvolvido do que diz respeito à tecnologia de materiais de construção, mas isto não invalida o uso de soluções simples como utilizar materiais da região de maneira a barateá-los, poupando energia do combustível, diminuindo a poluição causada pelo transporte, espalhamento de resíduo ao longo do trajeto e fortalecendo aspectos culturais.

$\mathrm{Na}$ breve incursão até o momento, podem-se identificar diversos aspectos, ainda que esparsos, mas que apontam para uma diversidade de situações geradoras de impactos ambientais relacionados à construção de casas e ao próprio ato de morar. O mesmo panorama elaborado aponta, ainda, que uma forma de atuação integrada, em todas as frentes de problemas ambientais associados à habitação, é algo muito complexo e que supera as possibilidades de uma atuação setorial.

Cada fase de um empreendimento imobiliário suscita determinadas questões a serem consideradas, a partir de impactos gerados por atividades desenvolvidas. Uma vez caracterizado os processos atuantes no meio ambiente e os impactos provenientes dos processos tecnológicos que compõem o empreendimento, em suas diversas fases, propõem-se instrumentos de gestão ambiental.

Quadro 2.1: Fases e etapas de um empreendimento habitacional

\begin{tabular}{|c|l|}
\hline \multicolumn{1}{|c|}{ FASES } & \multicolumn{1}{c|}{ ETAPAS } \\
\hline \hline Planejamento & $\begin{array}{l}\text { Caracterização da demanda } \\
\text { Seleção de áreas apropriadas } \\
\text { Confecção do Projeto }\end{array}$ \\
\hline \hline \multirow{2}{*}{ Construção } & $\begin{array}{l}\text { Movimentos de Terra } \\
\text { Edificação e demais obras } \\
\text { Áreas de Bota-fora } \\
\text { Paisagismo }\end{array}$ \\
\hline \hline Ocupação & $\begin{array}{l}\text { Uso e Ocupação (manutenção) } \\
\text { Adaptações e Ampliações }\end{array}$ \\
\hline
\end{tabular}

A implementação de um modelo de gestão ambiental adequado a um empreendimento habitacional de interesse social requer estudos que devem ser iniciados desde a concepção do projeto na fase de planejamento, passando pela sua construção e avançando continuamente durante toda a sua ocupação. Os requisitos ambientais em desenvolvimento no País, tanto legais quanto normativos, em especial os que se referem à Avaliação de Impacto Ambiental AIA (conforme ampla legislação correlata vigente) e ao Sistema de Gestão Ambiental - SGA 
(conforme normas técnicas nacionais e internacionais editadas), fornecem alguns fundamentos essenciais para o estabelecimento de um modelo de gestão integrada, ou seja, aplicável às relações do empreendimento com o meio ambiente desde sua origem e ao longo de toda sua vida útil.

Para a norma ISO 14001, a gestão ambiental abrange, como parte da função gerencial total, todos os setores na organização necessários ao planejamento, execução, revisão e desenvolvimento da política ambiental da organização. Traz benefícios internos (motivação dos colaboradores, prevenção de riscos e etc;) e externos (melhoria da imagem, fortalecimento da competitividade, facilidade com bancos e seguradoras e etc.). (DYLLICK et al., 2000, p. 15)

Com o desenvolvimento mundial nos setores social, econômico e tecnológico, aumenta para os usuários a necessidade de uma integração efetiva dos sistemas de gestão, o que seria facilitado com o desenvolvimento de critérios comuns válidos para todos os tipos de sistemas de gestão. A expansão dos SGIs é uma realidade, de acordo com o $12^{\circ}$ Ciclo da ISO Survey, pesquisa anual publicada recentemente pela International Organization for Standardization (ISO), revelou o total destes sistemas de gestão certificados em conformidade com as normas ISO 9000 (gestão da qualidade) e ISO 14001 (gestão ambiental) implantados em todo o mundo até o final de 2002: 611.209 certificados. Isto representa um crescimento de $11,6 \%$ em relação ao ano anterior, em que o total de certificados alcançou a marca de 547.381. (REVISTA FALANDO DE QUALIDADE, 2003, p.46)

Paralelamente ao lado ambiental, de caráter predominante externo, faz-se necessário os mesmos cuidados dentro da empresa, com os funcionários e com eventuais riscos a segurança da circunvizinhança. O BSI, British Standard Institute, elaborou um guia para o gerenciamento da segurança e saúde no trabalho (SST), baseado na norma ISO 14001, facilitando assim a integração dos sistemas. O BSI é uma instituição governamental semelhante a ABNT, Associação Brasileira de Normas Técnicas, no Brasil. A BS 8800 é uma diretriz britânica, logo não certificável e não possuindo, por conseguinte, acreditação do INMETRO.

A globalização provocou a integração dos mercados e a queda da barrreiras comerciais. Para grande parte das empresas, isso significou a inserção, muitas vezes forçada, na competição em grande escala. As empresas passam a investir em qualidade, primeiramente voltada para os produtos e posteriormente para os processos, até chegar ao tratamento abrangente das relações compreendidas na atividade empresarial, com os empregados, os fornecedores, os consumidores e clientes, a comunidade, a sociedade e o meio ambiente. 
Responsabilidade Social é uma forma de conduzir os negócios da empresa de tal maneira que a torna parceira e co-responsável pelo desenvolvimento social. . Posto isto, várias normas, diretrizes e padrões foram criados, como a Norma AA 1000, a SA 8000 e a GRI, contribuindo para criar um modelo de visão sobre as práticas de responsabilidade social e empresarial e sua gestão de desempenho. No Brasil, há o Instituto Ethos, que é uma iniciativa de padronização, além do modelo do Balanço Social proposto pelo IBASE.

Os modelos de gestão da qualidade internacionais não são aplicados para empresas altamente voláteis e turbulentas, cuja dinâmica das tecnologias de produto e processo são a tônica. É o caso das empresas do setor da construção civil, cujo caráter da produção apresenta peculiaridades que estão aquém do espectro de abrangência do escopo das normas ISO 9001.

\section{PLANEJAMENTO E IMPLEMENTAÇÃO DE EMPREENDIMENTOS EM EMPRESAS DA CONSTRUÇÃO CIVIL BASEADO NA SUSTENTABILIDADE.}

A instalação e o funcionamento de empreendimentos habitacionais de forma inadequada (projetos mal concebidos, desconsideração dos condicionantes do meio físico, análise sócio-econômica insuficiente, ausência de medidas de mitigação, entre outros aspectos) têm levado a situações de degradação ambiental no local de intervenção, causando prejuízos ao próprio empreendimento e gerando impactos ambientais que extrapolam a área do projeto. Isso acarreta redução da qualidade de vida da população e elevação significativa e desnecessária de custos para empreendedores, usuários, população circunvizinha e Poder Publico.

Neste ponto, o que se propõe é equacionar tais questões, por meio da adoção integrada de um sistema de gestão cujas medidas preventivas considerem, além do próprio empreendimento, os impactos ambientais que extrapolam a área de intervenção, através do ciclo PDCA de melhoria contínua baseada nos processos e na realidade do setor da construção civil rumo a eco-eficiência. Qualquer tentativa de gerir empreendimentos do setor da construção civil deve contemplar todas as fases de um empreendimento e toda a cadeia produtiva, convergindo para a qualidade, produtividade e conseqüente justiça social. 


\subsection{CARACTERÍSTICAS DO SETOR DA CONSTRUÇÃO CIVIL}

Nos últimos anos vêm sendo realizados grandes esforços no sentido de introduzir na construção a qualidade total já predominante em outros setores. Ocorre, porém, que a construção sustentável possui características singulares que dificultam a utilização na prática das teorias modernas da qualidade. Em outras palavras, a construção requer uma adaptação

Há uma grande complexidade inter-relacional, decorrente da diversidade e do número de intervenientes em cada operação, com capacidades técnicas e econômicas muito diferenciadas, interesses nem sempre convergentes e, muitas vezes, relações contratuais informais e pouco definidas. Tal fato desencadeou o surgimento de sistemas de gestão voltados exclusivamente para o setor da construção civil, inspirados no QUALIBAT (de origem francesa, 1992) e na série ISO 9000. Há necessidade de sistemas de gestão que absorvam as inovações de tecnologia e sejam mais adaptáveis a cada novo empreendimento, com suas particularidades quanto ao projeto do produto.

Segundo entrevista ao PBQP-H, (Programa Brasileiro de Qualidade e Produtividade no Habitat), publicada na Revista Qualidade na Construção, um dos fatores determinantes na criação do PBQP-H foi o episódio com o edifício PALACE II em fevereiro de 1998, onde ficou claro os prejuízos decorrentes da negligência com os parâmetros mínimos de qualidade dos materiais utilizados nas construções e a responsabilidade dos profissionais na condução das obras. (PBQP-H, 2004)

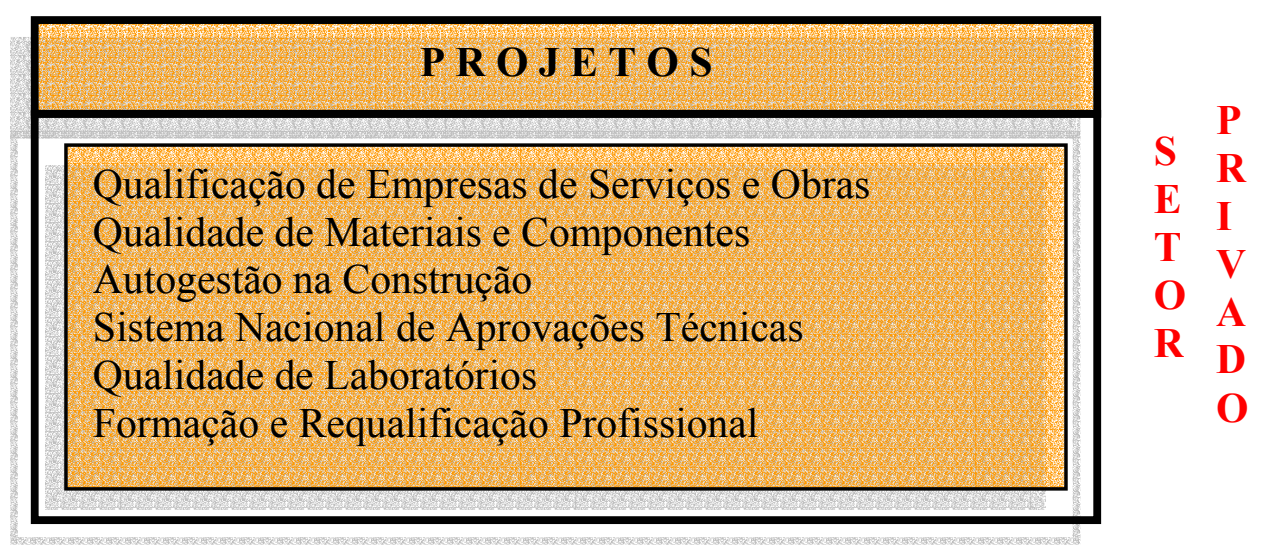

Figura 3.1Projetos desenvolvidos pelo PBQP-H 


\subsection{GESTÃO DO EMPREENDIMENTO - CICLO PDCA}

O ciclo PDCA é um instrumento valioso de controle e melhoria de processos que precisa ser de domínio de todos os funcionários da empresa. Mas antes de descrevê-lo cabe primeiramente a definição de processo: é um conjunto de atividades predeterminadas feitas para gerar produtos/serviços que atendam às necessidades dos clientes. Para tanto, todo processo utiliza insumos de fornecedores.

A empresa é um processo pois recebe insumos e produz produtos/serviços para atender às necessidades de seus clientes. Os departamentos que compõem sua estrutura e as atividades são igualmente processos.

O diagnóstico de uma empresa objetiva estudar os processos como um todo, visando detectar os pontos fortes que podem ser melhorados e os pontos fracos que necessitam ser corrigidos e depois aperfeiçoados. Trata-se de analisar o processo da empresa à luz do checklist, que aborda diversos requisitos que a empresa deve satisfazer para alcançar o objetivo desejado (preservação ambiental, produção limpa, saúde e segurança do trabalhador, responsabilidade e ética social, etc.).

O check-list poderia abordar os seguintes processos:

- Projeto;

- Aquisição;

- Gerenciamento e execução de obras;

- Operação e manutenção (uso e ocupação);

- Qualidade em recursos humanos.

Estes dados funcionam como subsídios para a concepção do Plano de Ação e sua posterior implementação, priorizando o ataque aos pontos em que a empresa apresenta maior debilidade. O que se pretende, é criar um raciocínio lógico, estruturado-o através do ciclo PDCA, melhoria contínua. O conceito deste método de melhorias PDCA encontra-se largamente difundido em escala mundial. Sua definição mais usual é como um método de gerenciamento de processos ou de sistemas utilizado pela maioria com o objetivo de Gerenciamento da Rotina e Melhoria Contínua dos Processos. Os trabalhos desenvolvidos sob esse enfoque abrangem, de maneira geral, empresas ligadas ao setor de manufatura, as quais foram as primeiras em adotar tal método de melhorias. 
Este método somente foi popularizado na década de cinqüenta pelo especialista em qualidade $W$. Edwards Deming, ficando mundialmente conhecido ao aplicar este método nos conceitos de qualidade em trabalhos desenvolvidos no Japão. Após refinar o trabalho original de Shewhart, Deming desenvolveu o que ele chamou de Shewart PDCA Cycle, em honra ao mentor do método (Walter A. Shewhart). O ciclo PDCA (Figura 3.2) é projetado para ser usado como um modelo dinâmico. A conclusão de uma volta do ciclo era fluir no começo do próximo ciclo, e assim sucessivamente. Seguindo no espírito da melhoria contínua, o processo sempre pode ser reanalisado e um novo processo de mudança poderá ser iniciado, gerando um real aproveitamento dos processos gerados na empresa, visando à redução de custos e o aumento da produtividade.

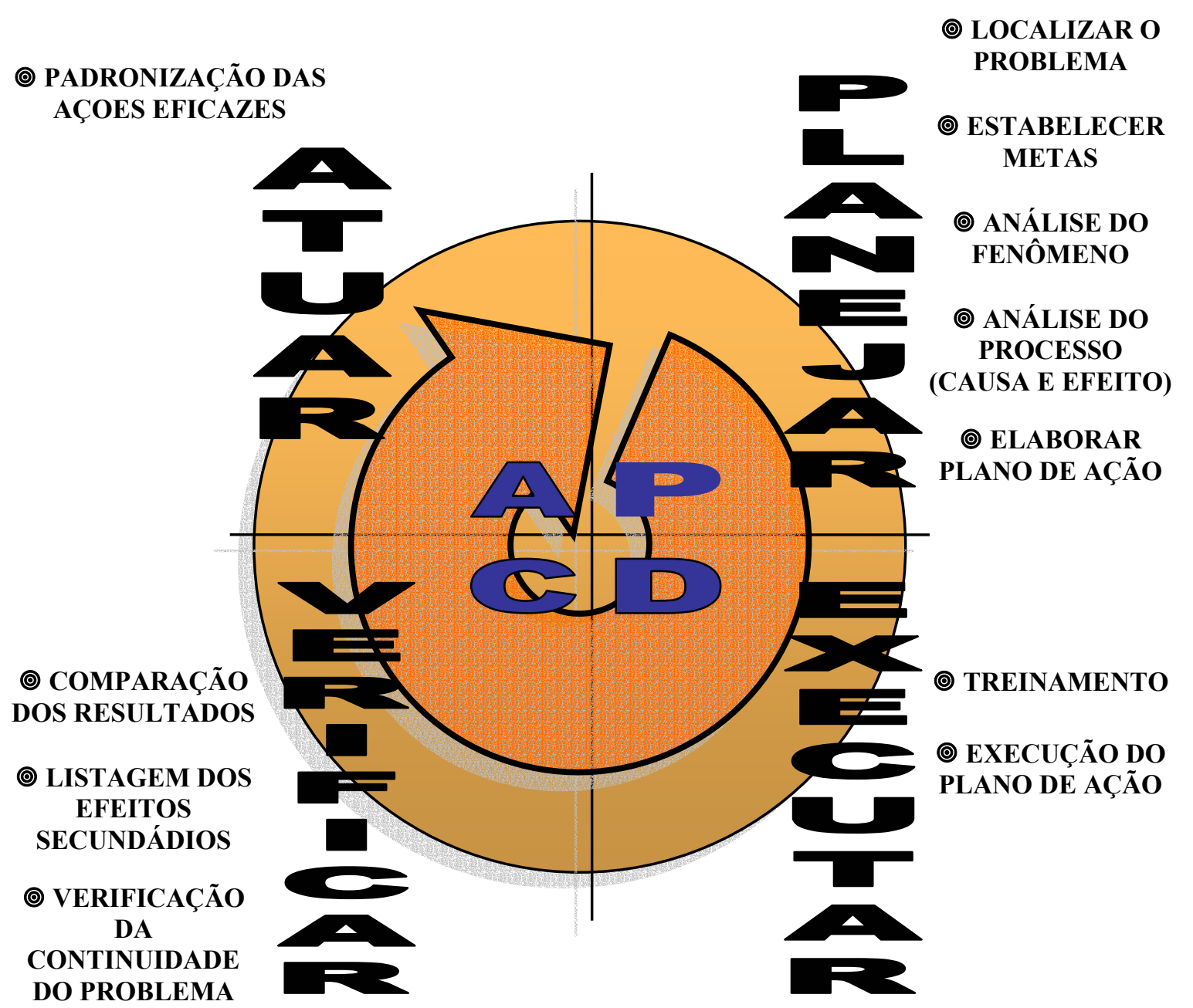

Figura 3.2: ciclo PDCA de melhoria contínua

Este ciclo ininterrupto de mudanças pode ser representado como uma rampa de melhoria. Usando o que foi aprendido em uma aplicação do ciclo PDCA, pode-se começar outro ciclo, em uma tentativa mais complexa, e assim sucessivamente. Sendo assim, o último ponto sobre 
o ciclo PDCA se torna o mais importante, onde o ciclo assumirá um novo começo. Somente aceitando isso como uma filosofia de melhoramento contínuo é que o ciclo PDCA literalmente nunca pára.

\section{PROPOSTA PARA ATINGIR A CONSTRUÇÃO SUSTENTÁVEL E A ECO-EFICIÊNCIA}

Diante do quadro geral das condições na indústria da construção civil e como forma de contribuição para a Política Habitacional Eco-eficiente, caracterizando a construção sustentável, necessária a preservação do meio ambiente, são propostas as seguintes linhas de ação a serem estruturadas:

\subsection{Implantar um sistema de gestão da qualidade pertinente com as características do setor da construção civil}

O Programa de qualidade e produtividade conhecido como PBQP-H (Programa Brasileiro de Qualidade e Produtividade no Habitat), é o mais indicado por envolver todas as etapas da cadeia produtiva configurada nos seus seis programas desenvolvidos, aumentando a competitividade do setor, incluindo a modernização técnica e gerencial das empresas.

O PBQP-H proporciona ganhos em toda a cadeia produtiva, gerando benefícios como: aumento da qualidade nos produtos; ganhos em produtividade pela melhoria nos processos de produção de materiais de construção e na execução de obras; moradia de melhor qualidade; redução dos custos através da redução dos desperdícios de material e melhoria na qualificação das construtoras; modernização tecnológica e gerencial através do fortalecimento da infraestrutura laboratorial e de pesquisa para desenvolvimento tecnológico; qualificação de recursos humanos e satisfação do cliente.

\subsection{Implantação de uma metodologia de trabalho na qual sejam consideradas todas as fases do empreendimento.}

A sustentabilidade de um empreendimento está comprometida com aspectos econômicos, sociais e ambientais, devendo levar em consideração desde a definição da demanda, na fase de planejamento, até a manutenção na fase de uso e ocupação. Os processos 
devem ser executados conforme planejamento prévio, fruto de projetos arquitetônicos feitos de maneira a minimizar o desperdício de material e conseqüente produção de sobras.

Propõe-se o uso da ferramenta chamada Produção Mais Limpa $(\mathrm{P}+\mathrm{L})$, que implica em evitar (prevenir) a geração de resíduos. Estes são gerados a partir da fase de construção, afetando o meio-ambiente e exaurindo seus recursos. Dessa forma, aprimora-se a eficácia dos processos, visando a redução ou eliminação da geração de resíduos e desperdícios durante o uso de matérias-primas, entre outras ações.

O cuidado com o meio ambiente deve se manifestar em todas as fases de um empreendimento, principalmente na fase de planejamento. Este módulo é considerado como o mais importante por ser o início do ciclo, desencadeando todo o processo referente à construção do empreendimento habitacional, erros cometidos nesta fase acarretam prejuízos ambientais, econômicos e sociais futuros. Ou seja, a sua eficácia está baseada em um planejamento bem elaborado e minucioso, o qual preverá dados e informações a todas as etapas restantes do processo como um todo.

Atenção especial deve ser dirigida à fase de uso, operação e manutenção, fazendo com que haja incremento na vida útil dos ambientes construídos através de uma visão preventiva. A avaliação de desempenho de ambientes construídos promove a ação (ou a intervenção), de maneira a gerar melhoria da qualidade de vida dos usuários do ambiente construído, e produz informações na forma de banco de dados, gerando conhecimento sobre o ambiente e as relações ambiente-comportamento.

Uma vez caracterizado os processos atuantes no meio ambiente e os impactos provenientes dos processos tecnológicos que compõem o empreendimento, em suas diversas fases, propõem-se instrumentos de gestão ambiental

\subsection{Utilização de Sistemas de Gestão Integrada (SGI) ao empreendimento.}

É necessária a adoção integrada de medidas preventivas, que considerem, além do próprio empreendimento, os impactos ambientais que extrapolam a área de intervenção e os aspectos sociais envolvidos. Tais medidas podem ser efetivadas, para cada fase do empreendimento, por meio de instrumentos de planejamento e gestão ambiental, os quais surgiram e vêm se desenvolvendo no bojo da evolução da abordagem da questão ambiental, e cujos princípios e procedimentos têm sido crescentemente adotados em diversos países. 
A responsabilidade social empresarial é um tema de grande relevância nos principais centros da economia mundial. Normas e padrões certificáveis relacionados especificamente ao tema da responsabilidade social, como as normas AS 8000 (relações de trabalho) e AA 1000 (diálogo com partes interessadas), vêm ganhando crescente aceitação.

A criação de "Indicadores" (sociais, econômicos, qualidade e ambientais), normas e padrões fazem parte do esforço em disseminar a responsabilidade empresarial no Brasil. Ao mesmo tempo em que servem de instrumento de avaliação para as empresas, reforçam a tomada de consciência dos empresários e da sociedade brasileira sobre o tema.

Dessa forma, propõe-se um Sistema de Gestão Integrada (SGI), eliminando redundâncias e assegurando consistência, através do uso de ferramentas (normas e diretrizes) de gestão voltadas para a qualidade (PBQP-H), meio-ambiente (ISO14001), higiene, saúde e segurança (BS8800, futura ISO18000), responsabilidade social com foco na contabilidade, auditoria e relato social e ético (AA1000) e direitos básicos dos trabalhadores (SA8000). Através de ações pró-ativas, pretende-se prevenir ao invés de remediar danos ambientais, gerando qualidade de vida a custos cada vez menores, trabalhando-se através da interdisciplinaridade caracterizada por aspectos sociais, ambientais e econômicos;

De modo a conjugar padrões técnicos- construtivos condizentes com melhores condições ambientais a um preço acessível à população de baixo poder aquisitivo, considerando-se também os aspectos sociais, impõe-se o desafio da contribuição tecnológica. Esta deverá se manifestar por intermédio de uma abordagem ambiental integrada corretiva e, principalmente, preventiva.

\section{CONCLUSÃO E SUGESTÃO DE NOVA PESQUISA}

A necessidade de abrigar-se remonta de longa data, desde a pré-história que o homem se esconde em cavernas para proteger-se dos seus agressores e das intempéries. Hoje não é diferente, o que mudou é o aumento de facilidades desenvolvidas ao longo dos anos, através de tecnologias que se aliaram às necessidades do homem. Até este momento, não havia vislumbre de problemas, porém o que antes parecia solução, hoje já se sabe, pode ocasionar grandes impactos ambientais.

A habitação com qualidade é uma necessidade que deve ser satisfeita sem comprometimento dos ecossistemas existentes, levando as empresas a assumirem uma postura ética de valorização do meio ambiente. A qualidade caracteriza-se a partir da definição da 
demanda, configurado no projeto através da satisfação dos aspectos sociais, econômicos e ambientais.

Medidas corretivas mostram-se onerosas financeiramente e socialmente devido à vultuosidade dos recursos necessários para reverter este quadro, com obras freqüentemente insatisfatórias em nível de desempenho. É necessária a adoção integrada de medidas preventivas, que considerem, além do próprio empreendimento, os impactos ambientais que extrapolam a área de intervenção e os aspectos sociais envolvidos.

Paralelamente a este cenário há uma nova perspectiva que vem se firmando e moldando o comportamento do empresariado. A questão ambiental atrelada à gestão empresarial é vista hoje não como modismo, mas como necessidade de sobrevivência dentro de um mercado competitivo e uma sociedade mais atenta aos seus direitos como consumidores e cidadãos.

Os impactos ambientais resultam não só de processos de produção, mas também aparecem em virtude da utilização de produtos, da sua destinação e posterior descarte, em virtude do transporte e do armazenamento. Deve-se pensar no produto em todo o seu ciclo de vida e nos impactos provocados ao meio ambiente, fazendo uso de ferramentas como a Produção Limpa.

O SGIs envolve todos os setores da empresa e mais um pouco, pois mexe com fornecedores, com clientes, não se limitando ao setor de meio ambiente da empresa.

Paralelamente ao lado ambiental, de caráter predominante externo, faz-se necessário os mesmos cuidados dentro da empresa, com os funcionários e com eventuais riscos a segurança da circunvizinhança. A grande vantagem em se implementar um Sistema de Gestão para Segurança e Saúde Ocupacional (BS 8800) tem sido a mudança de uma postura reativa, para uma postura preventiva. O Brasil, em função de sua história trabalhista, possui uma das melhores legislações referentes a Segurança e Saúde Ocupacional. Entretanto a legislação ainda tem uma característica reativa, por exemplo: acidentes com perda ou sem perda, taxas de gravidade e de freqüência, etc. (TAVARES, 2004)

Numa época em que os negócios não podem mais se dar em segredo absoluto, a transparência passou ser a alma do negócio, devido a isto, as entidades têm incluído a Contabilidade Social e seus indicadores como ferramenta de informação para a responsabilidade social. No Brasil, além do modelo do Balanço Social proposto pelo IBASE, há o Instituto Ethos que é uma iniciativa de padronização e que reúne atualmente centenas de empresas associadas de todos os setores e ramos de atividade, cujo faturamento somado é de cerca de $28 \%$ do PIB brasileiro. (ETHOS, 2004) 
As empresas do setor da construção civil apresentam peculiaridades que estão aquém do espectro de abrangência do escopo das normas ISO 9001. Já existem exemplos nacionais como o Programa Brasileiro de Qualidade e Produtividade do Habitat - PBQP-H, certificável, a nível nacional, flexível e baseado na norma ISO 9000.

No primeiro capítulo foram formuladas questões a serem respondidas ao final das pesquisas realizadas no desenvolvimento do presente estudo. Quanto à existência de pesquisas e estudos no Brasil a respeito do tema, há uma série financiada pelo FINEP. A grande maioria versa a respeito do desenvolvimento de produtos e processos. Uma parte bem menor trata sobre sustentabilidade na implantação de empreendimentos habitacionais eco-eficientes.

Não foi encontrado um enfoque tão completo quanto o apresentado neste trabalho, propondo uma gestão integrada de empreendimento, considerando aspectos ambientais, econômicos e sociais, com responsabilidade social e ética empresarial, e conseqüente ecoeficiência.

Há um segundo questionamento que versa a respeito do beneficio para o setor da habitação, sob o ponto de vista da eco-eficiência. São impactantes, na medida em que o setor da construção civil é o maior consumidor de matéria-prima e gerador de resíduos. Adotar um sistema de gestão integrada, de maneira a levar em consideração os aspectos ambientais (ISO 14000) para dentro dos empreendimentos habitacionais, normalmente com sua gestão da qualidade já implantada (ISO 9000), é altamente desejável na medida em que as normas são compatíveis e complementares. Dessa forma, reduz-se o desperdício e a geração de resíduos, incrementando a qualidade dos produtos e processo, maximizando a competitividade no setor.

Propõe-se, para dar continuidade ao presente tema desenvolvido, o estudo referente ao ambiente construído, através de mecanismos de controle de qualidade, tendo em vista o atendimento das necessidades de seus usuários. É este que irá detectar eventuais problemas no decorrer de sua vida útil, exigindo, se necessário, maior freqüência de manutenção de partes ou do todo, e, até mesmo a reposição ou eliminação daquele produto, caso se verifiquem problemas relativos a saúde, insalubridade ou risco de vida. Este contexto reduz a vida útil do ambiente construído e deteriora as relações humanas no espaço. Faz-se necessário reavaliar de forma científica toda esta produção no sentido de realimentar futuros projetos semelhantes, elaborar manuais de projeto, construção e manutenção de edifícios, além de complementar e atualizar códigos de edificações, recomendações técnicas e normas específicas sobre o assunto, minimizando possíveis impactos ambientais. 


\section{REFERÊNCIAS BIBLIOGRÁFICAS}

ABREU, Mauricio de A. Evolução urbana do Rio de Janeiro. 2. ed. Rio de Janeiro: IPLANRIO/ZAHAR, 1987. $147 \mathrm{p}$.

AGENDA 21 (1995). Conferência das Nações Unidas sobre o Meio Ambiente e Desenvolvimento. Brasília: Câmara dos Deputados, Coordenação de Publicações

ANDRETTA, Sérgio Roberto. Tecnologias limpas: como são originados os resíduos e suas emissões, porque os precessos geram ou transformam-se em resíduos e o que pode ser feito. Gerenciamento Ambiental, São Paulo: BJMoura Editora, ano 2, n.12, nov/dez 2002, p. 48-49.

BRUNDTLAND, Gro Harlem. Our souls are too long for this short life. Sustainable Development International, London, 1999. Disponível em: <http//www.sustdev.org>. Acessado em 10.12.2003.

CIMINO, Marly Alvarez. Construção sustentável e eco-eficiência. Santa Catarina: Universidade Federal de Santa Catarina, 2002. Disponível em:

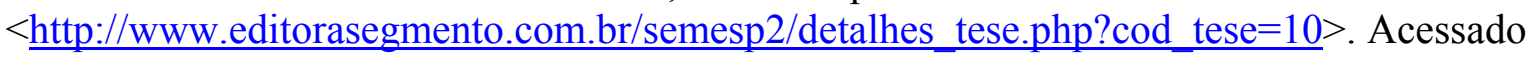
em 10.01.2003.

DYLLICK et al. Guia da Série de Normas ISO 14001: sistemas de gestão ambiental, Blumenau: Edifurb, 2000. 144p. Tradução de: Beate Frank, revisão: Ana Maria Bacca

ECO, Umberto. Como se faz uma tese. 17. ed. São Paulo: Perspectiva, 2002. 170 p.

EMPRESAS adotam processos ambientais investindo pouco. Revista Meio Ambiente Industrial. São Paulo: Editora Tocalino, p. 20-35, fev. 1999.

ETHOS ver INSTITUTO ETHOS DE EMPRESAS E RESPONSABILIDADE SOCIAL

FREITAS et al. Habitação e meio ambiente: abordagem integrada em empreendimentos de interesse social. São Paulo : Instituto de Pesquisas Tecnológicas do Estado de São Paulo IPT - Coleção Habitare, 2001. CD-ROM.

FURTADO, João S. Auditorias, sustentabilidade, ISO 14000 e produção limpa:

GONÇALVES, Robson R. O déficit habitacional brasileiro: um mapeamento por unidades da federação e por niveis de renda domiciliar. Rio de Janeiro: IPEA, 1998. $21 \mathrm{p}$.

GRAJEW, Oded. Filantropia de Responsabilidade Social. Ethos: 24 abr 2002, Disponível em: $<$ http://www.ethos.org.br>. Acesso em: 8 nov 2003.

GRIGOLETTI, G.C.; SATTLER, M. A. Impactos ambientais associados a materiais de construção: análise de ferramentas existentes. In: NUTAU 2002 - SUSTENTABILIDADE, ARQUITETURA E DESENHO URBANO, 2002, São Paulo. Anais...São Paulo, SP:Universidade de São Paulo, 2002. p. 1409-1420.

INSTITUTO ETHOS DE EMPRESAS E RESPONSABILIDADE SOCIAL. Indicadores ETHOS de responsabilidade social empresarial. Disponível em: 


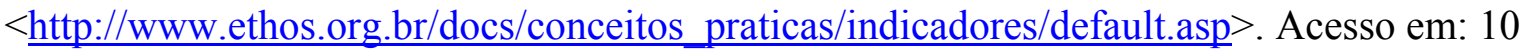
mar 2004.

MENDES, Maria Ceccato. Desenvolvimento Sustentável. Disponível em:

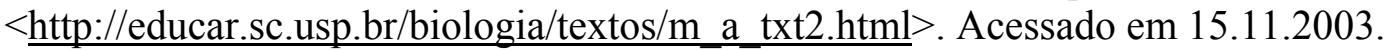

ORNSTEIN, Sheila; ROMÉRO, Marcelo. Avaliação pós-ocupação (APO) do ambiente construído. São Paulo: Studio Nobel: Editora da Universidade de São Paulo, 1992.

PBQP-H. Programa Brasileiro de Qualidade e Produtividade. Disponível em:

$<$ http://www.cidades.gov.br. $>$. Acesso em: 10 mar 2004.

PELIANO, José C. Pereira. Números da desigualdade e pobreza no Brasil. Disponível em: $<$ http://www.pt.org.br/assessor/pobres.htm>. Acessado em 28.05.2004.

REVISTA FALANDO DE QUALIDADE. Está chegando a hora: chegou a hora da ISO 9001:2002. São Paulo: EPSE, ano XIII, n.137, out 2003, 98p.

SALVATERRA. Conversando sobre a ISO 14001 e a BS 8800: O sistema de Gerenciamento Integrando a Qualidade de Vida ao seu Negócio. Disponível em:

$<$ http://www.salvaterra.com.br/documentos/conversando_sobre a iso_14001.pdf $>$. Acesso em: 20 abr 2004, 55p.

SENAI. Estudo setorial da construção civil: características estruturais do setor. Rio de Janeiro, 1995, 129p.

TAVARES, Luis Filipe Aboim. BS 8800-Evolução da reatividade para a prevenção.

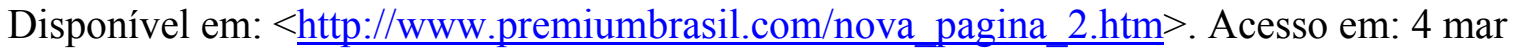
2004.

THIESEN, Marcos Pupo; KAWANO, Mauricy. Sistema de Gestão Integrado, Disponível em $:<\underline{\text { http: } / / \text { www.bolsafiep.com.br/revista/exibe news.asp? codigo }=57 \& p a g=69}>$. Acesso em 24 nov 2003.

\section{Artigo recebido em 01/09/04 e aceito para publicação e 15/06/05}

